4. Warren Spring Laboratory, Ministry of Technology The Investigation of Air Pollution. Monthly Summary (1973).

5. Ricks, G. R. \& Williams, R. J. H. Envir. Pollut. 8, 97-106 (1975).

6. Nieboer, E., Richardson, D. H. S., Puckett, K. J. \& Tomassini, F. D. in Effects of Air Pollutants on Plants (ed. Mansfield, T. A.) 61-85 (Cambridge University Press, London, 1976).

7. Ziegler, I. Residue Revs 56, 79-105 (1975).

8. Garsed, S. G. \& Read, D. J. New Phytol. 79, 583-592 (1977)

9. Bleasdale, J. K. A. Envir. Pollut. 5, 275-285 (1973).

\section{In vivo conversion of a labelled host plant chemical to pheromones of the bark beetle Ips paraconfusus}

\author{
L. B. Hendry* $\dagger$, B. Piatek $\ddagger \S$, L. E. Browne $\|$, \\ D. L. Wood $\|$, J. A. Byers $\|$, R. H. Fish $\uparrow \&$ R. A. Hicks**
}

* Departments of Medicine and Endocrinology, Section of Metabolic \& Endocrine Disease, Medical College of Georgia, Augusta, Georgia 30912

$\ddagger$ Department of Chemistry, Pennsylvania State University, State College, Pennsylvania 16802

|| Department of Entomological Sciences, University of California, Berkeley, California 94720

Energy and Environment Division, Lawrence Berkeley Laboratory, University of California, Berkeley, California 94720

** Department of Medicine, Medical College of Georgia, Augusta, Georgia 30912

Chemical constituents of host plants have been suggested to affect in part the ability of certain insects to produce sex pheromones, and thus their ability to reproduce'. We have investigated such a relationship between the bark beetle Ips paraconfusus (Coleoptera, Scolytidae) and its host tree Pinus ponderosa. The pheromone system of the insect is well characterised $^{2-4}$ and, as we report here, myrcene, a constituent of the host oleoresin system, is converted in the male beetle to its pheromones, ipsenol and ipsdienol. We used deuterium labelling techniques ${ }^{2}$ to demonstrate for the first time the unequivocal conversion of a host plant chemical to an insect pheromone.

I. paraconfusus males feeding on host phloem tissue produce three terpene alcohols which together are attractive to both sexes-ipsenol (Fig. 1, III), ipsdienol (Fig. 1, II) and cisverbenol. Myrcene (Fig. 1, I) was used because previous studies $^{5,6}$ had indicated that ipsenol and ipsdienol were produced in male but not female beetles when exposed to this terpene.

Myrcene (I) was labelled with deuterium by an unambiguous synthesis at the positions shown to avoid loss of deuterium on conversion to ipsenol or ipsdienol. The oxidation products could be identified by gas chromatography-mass spectroscopy (GCMS). Myrcene-D was prepared by the method of Westmijtze et $a l^{7}$. Reaction of 5-chloropent-2-one with methyl-magnesium iodide $\mathrm{D}_{3}$ produced 5-chlor-2-methyl-pent-2-ol. The alcohol was dehydrated with powdered sodium bisulphite to give 4 methyl-pent-3-enyl chloride (cis and trans isomers). The latter compound was converted to its cuprate and then added to vinylacetylene to produce myrcene-D. The identity of the products at each step was confirmed by NMR and IR and mass spectral analyses. The NMR of myrcene-D (Perkin Elmer R32, $90 \mathrm{MHz}$ ) indicated a deuterium content of approximately 1.6D in the methyl groups at 1.45 and 1.37 p.p.m. No deuterium was observable in any other position. Gas chromatography in conjunction with electron impact and chemical ionisation mass spectroscopy (EI- and CI-GC-MS) confirmed the presence of an isomeric mixture of myrcene- $D_{3},-D_{2}$, and $-D_{1}$ with myrcene- $D_{2}$ as the predominant isomer. The loss of deuterium was explained by exchange during the dehydration step.

† To whom correspondence should be addressed.

\$ Present address: Corporate Research/Analytical Services, Department of Analytical Chemistry, Ciba-Geigy Corporation, White Plains, New York 10502.
Ten bark beetles of each sex were sealed in separate $20-\mathrm{ml}$ ampules containing $10 \mu \mathrm{l}$ of myrcene-D for $18 \mathrm{~h}$ as before ${ }^{6}$. Abdomens were then removed and crushed immediately in diethyl ether. Extracts were analysed by electron impact and chemical ionisation GC-MS on $10 \%$ Carbowax $20-\mathrm{m}$ column using a Finnigan 4023 system. Peaks corresponding in retention time to ipsenol and ipsdienol, and possessing EI- and CI-GCMS spectra consistent with the expected fragmentation patterns of ipsenol-D and ipsdienol-D, were observed in extracts of males, but not females. Further analysis by EI- and CI-GC-MS, using a SP-1000 30-m capillary column, confirmed the presence of the two deuterated compounds in male extracts which had coincident retention times with standard ipsenol and ipsdienol. With the exception of the diagnostic pattern of deuterium incorporation, the $\mathrm{CI}$ mass spectra of both compounds gave pseudo molecular ions $(\mathrm{M}+1)$ and fragmentation patterns similar to ipsenol and ipsdienol. The relative isotopic abundance of deuterium at $\mathrm{M}+1$ for both compounds was also similar to that of deuterated myrcene. Clearly, these compounds were the hydroxylated products of labelled myrcene, deuterated ipsenol and ipsdienol.

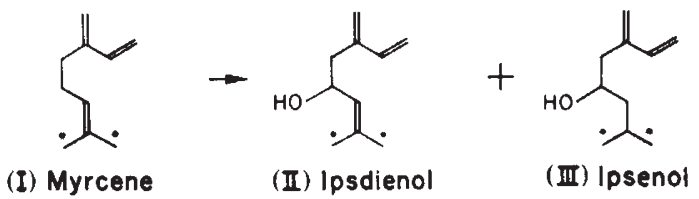

Fig. 1 Structures of myrcene, ipsdienol and ipsenol. Asterisks indicate positions of deuteration.

We conclude that male $I$. paraconfusus can convert myrcene, a terpene hydrocarbon from its host plant, to its pheromones, ipsenol and ipsdienol. Moreover, the presence of other labelled metabolic products in both sexes and the absence of labelled ipsenol and ipsdienol in the female demonstrate the sexual specificity ${ }^{2.6}$ of the biosynthesis of the pheromones. Although we cannot rule out completely alternative pathways (such as de novo pheromone biosynthesis, the conversion of other terpene hydrocarbons to pheromones, or induction of pheromone secretion), our results coupled with the observation by Hughes $^{5,8}$ and Byers et al. ${ }^{6}$ that ipsenol and ipsdienol are found only in $I$. paraconfusus males exposed to myrcene, support the primacy of host chemicals in pheromone production. If Renwick's demonstration of enantiomeric specificity ${ }^{9}$ in the production of $c i s$-verbenol (the non-sex specific component of the pheromone of male I. paraconfusus) on exposure to $(-) \alpha$ pinene is also a direct biosynthetic step, then all three known pheromone components may be derived from the host plant by simple oxidation of available chemicals. Experiments with isotopically labelled $(-) \alpha$-pinene may provide support for this premise. Thus, the evolution of host plant preferences in bark beetles may be a consequence in part of the chemistry of the tree as it affects pheromone biosynthesis.

This work was supported in part by grants from the Rockefeller Foundation (to L.B.H. and D.L.W.), and US Forest Service and Regional Research Project W-100, SEA/USDA (to D.L.W.). We thank Ron Skinner of Finnigan Corp. for technical expertise.

Recieved 24 September 1979; accepted 3 January 1980

1. Hendry, L B. et al. Biochemical Interaction Between Plants and Insects, 351-384 (Plenum, New York, 1976).

. Fish, R. H., Browne, L. E., Wood, D. L. \& Hendry, L. B. Tetrahedron Letr. 17, 1464-1468 (1979).

3. Silverstein, R.M. Rodin, J. O \& Wood, D. I Science 154, 509-10 (1966).

4. Silverstein, R. M., Rodin, J. O., Wood, D. L. \& Browne, L. E. Tetrahedron 22, 1929-1936 (1966).

5. Hughes, P. R. J. Insect Physiol. 20, 1271-1275 (1974)

6. Byers, J. et al. J. Insect Physiol. 25, 477-482 (1979).

7. Westmijze, H., Kleijn, H., Meijer, J. \& Vermeer, P. Tetrahedron Lett. 869 (1977)

8. Hughes, P. R. \& Renwick, J. A. A. Physiol. Ent. 2, 117-123 (1977).

9. Renwick, J. A A. Hughes, P. R \& Krull, I. S. Science 191, 199-201 (1976). 